\title{
The Psychological Relationship between Companies and Freelancers: An Empirical Study of the Commitment and the Work-related Expectations of Freelancers ${ }^{* *}$
}

For some years now a tendency towards a more flexible shaping of employment has been observable. Little research, however, has been dedicated to the question of how relevant this is for the commitment of freelance employees. Therefore the present paper first reverts to the question as to whether - and if so, under what preconditions freelancers are likely to feel commitment towards the company that employs them. Second, the paper identifies clusters of freelancers following their work-related expectations. On the basis of an empirical study among IT-freelancers it becomes clear that freelancers differ from permanent employees as regards their work-related expectations. Consequences for their felt commitment hence ensue. All in all it is mainly an affective commitment towards their company which they perceive.

Key words: Commitment, Flexible Employment Forms, Freelanced Employees, Work-related Expectations

* Dr. Stefan Süß, Markus Kleiner (M.A., DESS), University of Hagen, Faculty of Applied Economics, Department of Business Administration, Profilstraße 8, D - 58093 Hagen, Germany, e-mail: Stefan.Suess@FernUni-Hagen.de, Markus.Kleiner@FernUni-Hagen.de.

** Article received: January 15, 2007

Revised version accepted after double blind review: September 17, 2007. 


\section{Introduction}

On the German labour market, clear tendencies of a transition to more flexible employment forms can be detected in recent years. This leads to far-reaching changes in the workforce structure of many companies: Tasks are no longer accomplished within companies but rather outsourced to specialists who perform at higher levels of efficiency. Within the outsourcing companies workplaces become obsolete and a segregation from permanent employees ensues (Storey/Salaman/Platman 2005). Against this background, it is not surprising that a continuous turning away from the so called regular employer-employee ${ }^{1}$ relationship may be observed in recent years. In Germany, these employments are understood as a durably conceived relationship that is based upon a perpetual contract and carried out in full time.

Different atypical employments take the place of regular employer-employee relationships. Temporary work (contracts) and part-time employment can already be noticed for some time. Besides, a tendency towards self-employment may be detected in recent years. It is discussed in literature and corporate practice under different notions as new self-employed or freelance. Data gained by the German Institut für Arbeitsmarkt- und Berufsforschung (institute for labour market and job research) (IAB) demonstrate that about $40 \%$ of all employees are not employed in a regular employeremployee relationship (Hoffmann/Walwei 2002). The number of freelancers in Germany is estimated to be round about two million with an increasing tendency (Moldaschl 2003: 109).

The notion "freelancer" is not clearly defined in Germany, neither from a juridical (social law) nor from an economic (business administration) perspective. It can hence not be excluded that its usage in corporate practice shows overlapping with other forms of atypical employment. In corporate practice freelancers are seen as people who perform in a personal, self-dependent and - irrespective of professions - intellectually ideal way for their employer. The employer can be a company as well as other individuals. As a rule, freelancers are specifically qualified - e.g. as an IT-freelancerand are to be flexibly employed as regards time or location (Freelancerverband 2004). In Germany, highly qualified freelancers are particularly represented in media (journalists at the press, radio or television), in consulting firms, and in the IT-industry (Statistisches Bundesamt 2003: 72-73).

As a consequence of more flexible employment forms, permanent staff in companies diminishes while peripheral staff increases (Torka/Looise/Van Riemsdijk 2005). On the one hand, companies benefit through economic advantages. They particularly consist in a reduction of fixed labour costs and supplementary costs, higher flexibility and an externalisation of the risk of fluctuating utilisation. On the other hand, numerous indicators are to be found for negative changes in the social and psychological relationship between companies and freelancers. As a result of the expected flexibility and their rather lose, temporary contractual relationship to a company it is argued that freelancers may show - considerably - less identification and loyalty to a

1 Although the male form is used for simplicity reasons, it is to be understood neutrally in terms of gender and explicitly refers to women and men. 
company than permanent employees (Anderson/Schalk 1998; Pfeffer 2005). Kulkarni and Ramamoorthy even assume a trade-off between flexibility of employment form on the one hand and employee commitment on the other hand: With a growing flexibility the commitment declines (Kulkarni/Ramamoorthy 2005: 741), leading to an emotional disengagement of employees from the company (Felfe et al. 2005: 102; Pfeffer 2005: 4-5). This assumption is substantiated by the limited employment period in the company in the first place which renders it difficult to establish commitment, i.e. identification and an emotional link with a company (Pfeffer 2005). Williamson already stated at an early stage that economic detriments may be linked to that. He sees a crucial advantage for companies in the larger commitment that may arise in regular employer-employee relationships (Williamson 1975: 38). However, research on commitment focuses mainly on permanent employees. The psychological relationship between companies and freelancers has been researched in an empirical way at best rudimentarily up to now. For atypical employment forms - and especially for freelancers - a deficit in research still has to be stated. However, as a consequence of the growing importance of freelancers it gains in relevance (Gallagher/McLean Parks 2001: 204).

Against this background, the research aims of this paper are twofold. First, this paper seeks to examine whether freelancers feel commitment towards a company and under which preconditions this applies. Second, this paper seeks to analyse which workrelated expectations freelancers have regarding their employment. In this context a classification of different freelancer groups is carried out in order to gain more differentiated insights as regards the work-related expectations of different freelancers and differences in their psychological relationship to the employing company. The empirical section of the paper refers to the results of an internet-based survey of 150 German IT-freelancers.

\section{Antecedents, Consequences and Dimensions of Commitment}

Commitment is defined as "the relative strength of an individual's identification with, and involvement in, a particular organization" (Mowday/Porter/Steers 1982: 27). It circumscribes a particularly intensive, non-contractual relationship between an individual and a company and is figuratively referred to as a "psychological tie" in places (Moser 1997). Commitment comprises the voluntary obligation and willingness of an employee to bind himself to a company beyond contractually regulated guidelines. It plays a vital role for the engagement and dedication of individuals. For regular employer-employee relationships it is held true that commitment enhances the performance of employees while it reduces their fluctuation, absenteeism and their felt stress (Mowday/Porter/Steers 2005: 179-187; Riordan/Vandenberg/Richardson 2005).

In the corresponding literature different determining factors and antecedents of commitment respectively are discussed (Mathieu/Zajac 1990; Fig. 1): Firstly, commitment is influenced by individual demographic characteristics and personality traits such as age, sex, qualification, seniority, status, and remuneration of an employee. Secondly, differing working conditions (job or task characteristics, relationship with superior or colleagues) have an effect on commitment. A direct impact thereby results from the actual state regarding the working conditions as perceived by an employee, whereas a 
positive perception fosters the felt commitment. However, it has to be seen that the assessment of the actual state may be put into perspective by individual expectations that define the aspiration level of an individual. Commitment may hence be influenced by exceeding or disappointing the aspiration level (Meyer/Allen 1987).

Furthermore, two co-variegating variables of commitment are discussed in the literature. On the one hand, they concern the motivation of employees; motivation and commitment display an interdependent relation since commitment also influences job motivation. On the other hand, the subjectively felt job satisfaction represents a covariegating variable of commitment. Empirical studies confirm a reciprocal relation and mutual interaction (Felfe et al. 2005: 105).

Figure 1: Determining factors, co-variegating variables and consequences of commitment

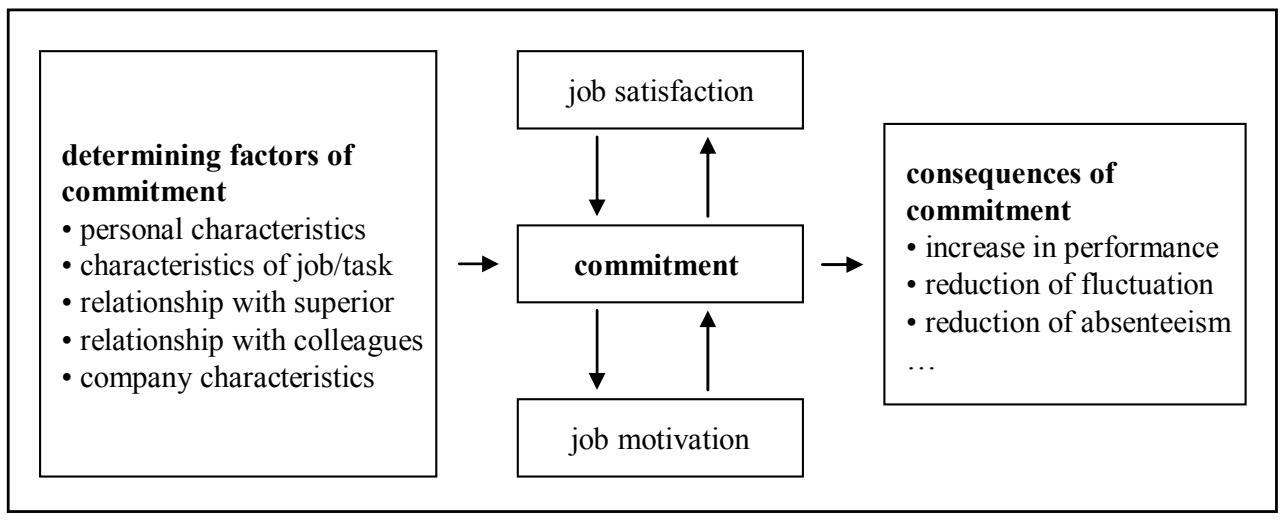

In research on commitment two concepts prevail: In the behavioural approach commitment is considered as bonding to actions and behaviour (Salancik 1977). In contrast to that, in the attitude approach, it is interpreted as extensive identity of organisational and individual values whose results are the identification with and the engagement in an organisation. This leads to the desire to engage in reaching organisational objectives and to remain in the organisation (Porter et al. 1974; Meyer/Allen 1991). The attitude construct nowadays forms the basis of large parts of the research on commitment which is why this essay also bases on it.

In the attitude construct organisational commitment is commonly seen as a multidimensional construct split into affective, calculative and normative commitment (Meyer/Allen 1991):

- Affective commitment (AC) means an emotional bond of an employee towards his company as well as his identification with it. In these cases, commitment is based upon positive emotions such as joy or pride. Central influences of the affective commitment are work experiences like leadership behaviour of a superior and specific job characteristics.

- Calculative commitment (CC) rests upon a rational input-output-calculation. A bond arises if an individual that considers employment alternatives becomes aware that leaving the company would be linked to economic detriments. 
- Normative commitment (NC) relies on individual convictions that are opposed to quitting the company. It may result from values or felt duties towards people or institutions, for example.

Surveys confirm the three dimensions of commitment. These however prove to be independent from one another only to a limited extent. A significant correlation in particular exists for affective and normative commitment $(\mathrm{r}=0.51$; Allen/Meyer 1990). It is also confirmed in our survey $(r=0.49)$. Nonetheless, commitment research largely refers to affective, calculative and normative commitment as well as to the questionnaire by Allen and Meyer. Thus, the subsequently described survey also refers to this approach and questionnaire.

\section{Methodology}

\subsection{Research design}

The first research aim of this paper is to examine whether freelancers feel commitment towards a company and under which preconditions this applies. To give an answer to this question, possible (immediate) factors fostering the freelancers' commitment - i.e. the examined independent variables - were derived from the literature. The variables were summarised in two categories (personal characteristics and working conditions). On the basis of results gained from other empirical studies on commitment, hypotheses were formulated regarding the effect of the respective variables. A verbal explanation of all of the assumed effects has been dispensed with for brevity reasons. Some of the underlying studies are however specified in figure 2. The assumed direction of the effects of the independent variables is indicated through "+" (positive effect) and "." (negative effect) respectively.

The argumentation that underlies the following figure 2 shall be clarified by an example: Regarding the personal characteristic "qualification" Mathieu/Zajac found in an empirical survey that the employer-related commitment decreases with an increasing qualification (Mathieu/Zajac 1990) since highly qualified people rather feel commitment towards their occupational group than towards a company. It is therefore assumed that the employer-related commitment of a freelancer decreases with his increasing qualification. Correspondingly, this assumption is expressed through a minus in figure 2. Substantiated by the cited references, the coherences of the other investigated variables with the commitment of IT-freelancers are presented accordingly. As regards the variable sex, studies yielded that the commitment of women is higher than that of men (Gould 1975; Bruning/Snyder 1983). This is indicated in figure 2 through a plus in respect to the variable value "female". Therefore, the variable value "male" shows a negative coherence with commitment.

Furthermore, two co-variegating variables of commitment are discussed in the literature: Motivation and job satisfaction of the employees. These co-variegating variables were not explicitly surveyed as this would have extended the already extensive questionnaire considerably and, hence, probably lowered the response rate.

The second research aim of this paper is to analyse which work-related expectations freelancers have regarding their employment. On the one hand, this is necessary as there commonly is only little information available in this area and a deficit in re- 
search can be stated. On the other hand, work-related expectations represent a vital determining factor of commitment through their compliance or disappointment (Meyer/Allen 1987). By considering them, the co-variegating variable job satisfaction may at least be pictured approximately: Job satisfaction occurs if the positive consequences of behaviour correspond at least with the individual expectations in a specific work situation so that needs are met and expectations are fulfilled. Job satisfaction fails to appear if expectations are not fulfilled.

Figure 2: Research design

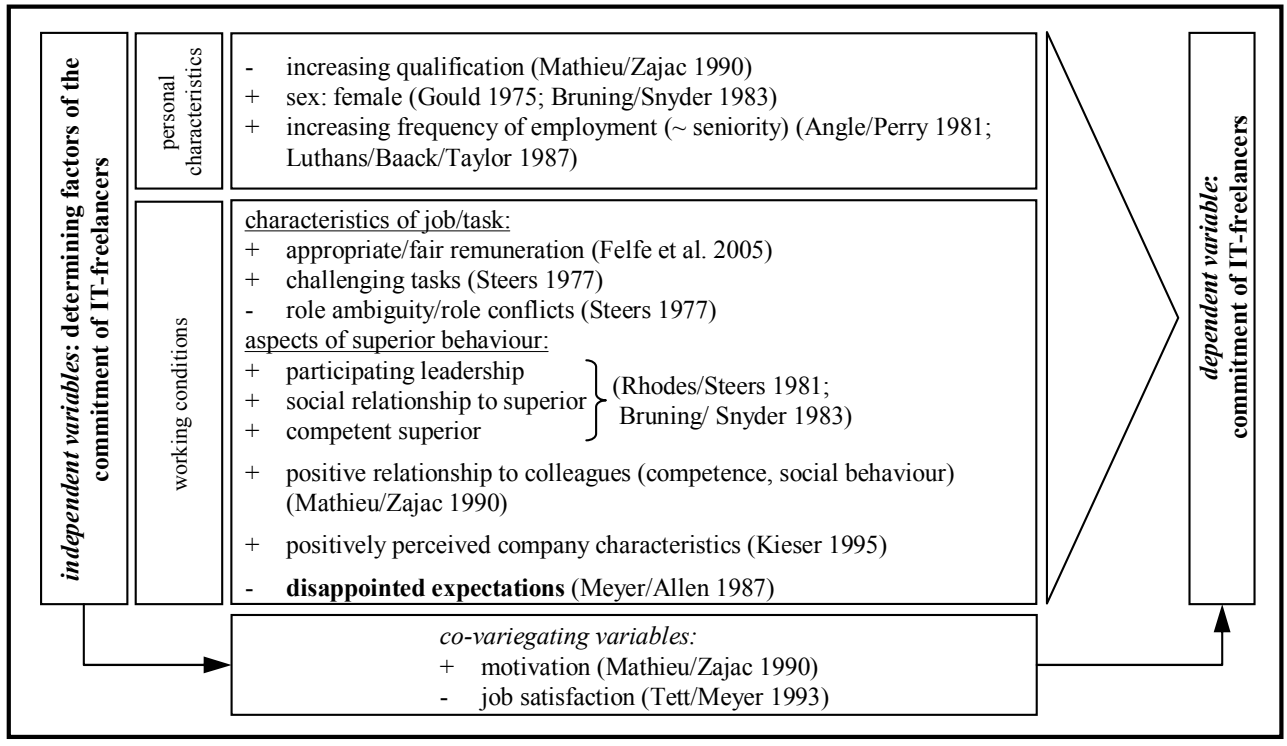

Gobal statements as regards the work-related expectations of freelancers prove to be too unspecific since research on motivation states that people differ concerning their (work-related) expectations (Atkinson 1957; Vroom 1964; Herzberg/Mausner/Synderman 1967). Reasons for that are to be traced back to the respective personality, to experiences as well as to processes of socialisation. Against this background it seems however rational that different groups of freelancers may be identified which show dissimilar work-related expectations. The examined freelancers shall therefore be classified based on their work-related expectations in order to allow for more differentiated results regarding their commitment and its determining factors.

\subsection{Data collection and sample}

While freelancers have been employed in the media industry for quite some time (Storey/Salaman/Platman 2005), their employment in the IT-industry has gained considerable momentum only in recent years. Although accurate data on the number of ITfreelancers in Germany is missing, according to estimations it reached about 70.000 in 2002 while further increases were expected. The study focussed on IT-freelancers due to their relatively high and increasing importance. The empirical study comprised two steps: In the first step, a pre-test was carried out. For this purpose some IT-freelancers were interviewed. This was necessary in order to ascertain if the questionnaire that had 
so far only been used for regular employment relationships might in principle also be applied for freelancers. Misconceptions arose since the questionnaire comprised questions that could not be answered offhand due to the different situation of freelancers. Verbal modifications as well as deleting some of the questions therefore became necessary.

In the second step the actual quantitative freelancer survey followed from November 2003 until January 2004. It was carried out in an online-survey that was explicitly addressed to IT-freelancers. The survey was announced in corresponding Germanspeaking professional journals and in the Internet. The questionnaire was only available online for almost two months. Respondents were asked to refer to the company by which they were predominantly employed at that point of time or to the last company they worked for.

386 people visited the survey web page, 150 people participated in the survey and completed the questionnaire in full. $92 \%$ of respondents are male, the average age of respondents is at about 36 years. The majority of respondents have graduated from a university $(59.3 \%)$ or have completed a vocational education (20\%). On average, the questioned IT-freelancers have been working freelance for about 6 years and have hitherto been employed by 7.6 different employers. The company they have been working for at the time of the survey has already employed them - temporarily - for 3.9 times on average. The completed jobs commonly demanded specialised ITknowledge which points out the comparatively high specificity of tasks carried out by freelancers.

\subsection{Measures}

The commitment scale by Allen and Meyer (1990) was used in the first part of the questionnaire. In contrast to the commitment questionnaire by Mowday/Porter/Steers (1982), it offers the advantage of also capturing the calculative and normative component besides the affective commitment. The scale by Allen and Meyer had however to be adjusted to some extent as a result of pre-test findings. Despite necessary adjustments its employment in a freelance context can be justified for two reasons: Firstly, literature on commitment offers no alternatives that are acknowledged for atypical employeremployee relationships. Secondly, the application of this standardised scale renders a comparison with other surveys possible. In the context of the freelancer survey, the reliability of the utilised commitment scale proved to be good (Cronbachs $\alpha$ (standardised $)=0.78$ ). The three partial scales of commitment proved to be relatively independent; their average intercorrelation ranges at $\mathrm{r}=0.38$ with a probability of error of $1 \%$ (intercorrelations: $\mathrm{AC} / \mathrm{NC} \mathrm{r}=0.49 ; \mathrm{CC} / \mathrm{NC} \mathrm{r}=0.42 ; \mathrm{AC} / \mathrm{CC} \mathrm{r}=0.22$ ).

Personal characteristics of freelancers (demographic and statistical data) were surveyed in the second part of the questionnaire: (1) Their formal qualification (as differentiated in university degree, technical education, A-levels, certificate of secondary education, and no certificate), (2) the duration of employment as measured by the number of assignments for the company the respondent was working for at that time, (3) the duration of their overall freelance engagement, (4) the number of hitherto employing companies, (5) the sex of respondents and (6) their age. 
The third part of the questionnaire comprised established scales of different work analysis techniques (Hackman/Lawler 1971; Hackman/Oldham 1976). On the one hand, they were used to identify the work-related expectations that freelancers address to a company ("aspects that are important for freelancers") (Cronbachs $\alpha$ (standardised) $=$ 0.81). On the other hand, the actually perceived working conditions could be raised ("assessment of working conditions"). This was carried out through five-point Likert scales which referred to (1) remuneration (appropriateness, fairness), (2) challenges of job (work content), (3) role of freelancer (clarity of roles and tasks, role conflicts), (4) relationship with colleagues, and (5) company characteristics (company image, well equipped workplace, possibility to gain knowledge, corporate culture). Moreover, the scales referred to the de facto superior. Although a hierarchical superior does not exist for independent cooperation partners of companies, there generally is a manager who is responsible for task assignment, information provision and performance control. Freelancers were asked to assess (6) the leadership of their de facto superior as regards the level of participation, (7) the relationship with their de facto superior, and (8) the competence of their de facto superior. The reliability of all scales turned out satisfactory (average Cronbachs $\alpha$ (standardised) $=0.75$ ). However, the used scales were partly interdependent. The strongest correlations exist between the social relationship with the de facto superior and the corresponding leadership $(r=0.78)$ as well as the corresponding competence $(\mathrm{r}=0.56)$ of the de facto superior. The same applies for remuneration and company characteristics $(r=0.68)$. The average intercorrelation of all scales is however at $\mathrm{r}=0.30$ and, hence, on a maintainable level.

\section{Results and discussion}

\subsection{General findings on the commitment of freelancers}

Data analysis is in the following presented in several steps. Firstly, general descriptive findings on the commitment of freelancers are presented. In this context comparisons are carried out with the findings of other studies. Secondly, work-related expectations of freelancers are scrutinised. A factor analysis renders an aggregation of data possible. Third, cluster analysis is used in order to classify different freelancer groups following their work-related expectations. They are then described in larger detail through descriptive demographic data. Fourth, the relation between the determining factors of the commitment of freelancers (independent variable) and their commitment (dependent variable) are detected by use of correlation and regression analyses. This is effected for both the overall data and the freelancer groups as differentiated in the third step.

The survey clarifies that freelancers may feel commitment towards their company. However, it shows the necessity to differentiate as regards the three commitment dimensions (fig. 3).

A comparison of means (scale from 1 "very high" to 5 "very low") shows that the affective commitment (2.50) is more pronounced than the normative (2.99) and the calculative commitment (3.31). The results are consistent with other studies. In principle, Allen/Meyer assume that the affective commitment component shows the strongest correlations with working conditions, work-related expectations, job satis- 
faction and performance (Allen/Meyer 1990). Research from the German-speaking area confirms this assumption (Schmidt/Hollmann/Sodenkamp 1998).

Figure 3: Importance of commitment-related statements for IT-freelancers

\begin{tabular}{|c|c|c|c|}
\hline dimensions of commitment & agreement & partly & no agreement \\
\hline $\begin{array}{l}\text { affective commitment } \\
\text { 1) I would be very happy to spend the rest of my career with this organisation. } \\
\text { 2) I am proud to work for this organisation. } \\
\text { 3) I feel affiliated to this organisation (no comment } 0.5 \% \text { ). } \\
\text { 4) I do not feel emotionally attached to this organisation. } \\
\text { 5) I think that my moral concept is in line with the moral concept of this organisation. }\end{array}$ & $\begin{array}{l}82,0 \\
50,0 \\
44,0 \\
18,0 \\
48,0\end{array}$ & $\begin{array}{l}15,3 \\
27,3 \\
24,0 \\
30,0 \\
27,3 \\
\end{array}$ & $\begin{array}{c}2,7 \\
22,7 \\
31,5 \\
52,0 \\
24,7\end{array}$ \\
\hline $\begin{array}{l}\text { calculative commitment } \\
\text { 6) I feel that I have too few options to consider leaving this organisation. } \\
\text { 7) I have already invested energy into this organisation. It would hence be } \\
\text { reasonable to work for this organisation again in the future. } \\
\text { 8) If I did not work for this organisation again ... } \\
\text { a) ... it would require considerable personal sacrifice. (no comment } 6.7 \% \text { ) } \\
\text { b) ... many things in my life would be disrupted. (no comment } 4.7 \% \text { ) }\end{array}$ & $\begin{array}{l}32,0 \\
53.3 \\
16,0 \\
17,3\end{array}$ & $\begin{array}{l}27,3 \\
26,0 \\
26,0 \\
12,0\end{array}$ & $\begin{array}{l}40,7 \\
20,6 \\
51,3 \\
66,0\end{array}$ \\
\hline $\begin{array}{l}\text { normative commitment } \\
\text { 9) I think it is right to work for this organisation again. } \\
\text { 10) It does not make a good impression as a freelancer to work only once for an } \\
\text { organisation. } \\
\text { 11) I would work for this organisation again since I feel obliged to some people to do so. } \\
\text { 12) If I did not work for this organisation again, a lot of people who are important to me } \\
\text { would be disappointed or would not understand it. (no comment } 3.7 \% \text { ) }\end{array}$ & $\begin{array}{l}68,0 \\
39.3 \\
45,3 \\
15,0\end{array}$ & $\begin{array}{l}24,0 \\
23,3 \\
25,3 \\
12,0\end{array}$ & $\begin{array}{l}37,3 \\
29,3 \\
69,3\end{array}$ \\
\hline
\end{tabular}

For a better understanding of the absolute results, a comparison with other studies that are based on the questionnaire by Allen/Meyer is necessary. As it concerns a standardised survey method this is basically possible. However, limitations have to be taken into account when comparing with other commitment research: Firstly, in detail the questionnaire is translated differently. Secondly, variously staged Likert scales are used. Thirdly, the context of surveying varies with different employment and assignment circumstances of the respondents (e.g. freelancers, permanent employees). Thus, it cannot be ruled out that meanings, connotations and interpretations are perceived differently. This probably leads to the most important restrictions for a comparison of different studies.

If a comparison is carried out despite these limitations, differences of individual commitment dimensions become clear. For permanent employees of the administration of the German federal states (Schmidt/Hollmann/Sodenkamp 1998) as well as employees in American companies and American organisations of the church (Meyer/Allen 1991) the calculative is higher than the affective commitment which in turn is higher than the normative commitment. A German study of permanent employees in the IT-sector however shows that their affective commitment exceeds their calculative or normative commitment (Six et al. 2002). By comparing the results of our IT-freelancer survey, it attracts attention that the calculative commitment of ITfreelancers corresponds approximately with the calculative commitment of permanent employees. It however falls short of the affective and normative commitment of respondents of the other two studies. All in all, the commitment detected in other studies proves to be stronger (Allen/Meyer 1990; Schmidt/Hollmann/Sodenkamp 1998: 
98; Six et al. 2002). In the light of freelancers changing or having changed the company more frequently than permanent employees the lower level of commitment is not surprising (Pfeffer 2005: 20).

Regarding the first research question - whether freelancers feel commitment to a company - one may state that respondents feel commitment against the background of first descriptive results. In comparison to other studies, it is neither particularly higher nor lower. As in other studies, the affective commitment is the strongest commitment component. In the following analysis it is to be seen which conditions determine the commitment of freelancers (see section 4.4 of this paper).

\subsection{Work-related expectations of freelancers}

In the questionnaire typical work-related expectations of IT-freelancers were detected on a five-point Likert scale ranging from 1 "very important" to 5 "unimportant". A test following the Kaiser-Meyer-Olkin measure showed that the sample was adequate for a factor analysis. Thus, through an explorative factor analysis across all items, structures between the items could be identified and an aggregation of data became possible. The factor analysis was conducted as a principal component analysis whereas the number of factors was determined following the Kaiser criterion (Eigenvalue $>1$ ). An orthogonal varimax-rotation rendered a factor solution of six factors that cumulatively account for about $65 \%$ of overall variance; an alternative non-orthogonal (oblimin) rotation resulted in identical item-factor structures. The main loadings of the items were higher than 0.4 which is seen as the critical value; their side loadings were below 0.4 in all cases so that a clear assignment to one of the six factors was possible. As a result, six groups of expectations (factors) could be identified (fig. 4).

Factor 1 ("social and cooperative working atmosphere") exhibits the importance of social aspects in the context of an employment as a freelancer. This concerns personal characteristics of superior and colleagues as well as the work situation (exchange of information, conflict resolution, work surroundings). It shows that the questioned freelancers apparently have the need to feel comfortable in the company and do not exclusively follow monetary, remuneration-related objectives. The expectation of a challenging job (factor 2 "challenging tasks") may be explained by the fact that IT-freelancers were surveyed that commonly have a high level of education. In this respect, the expectation of a comparatively demanding job is linked to that. Moreover, the possibility to obtain further qualification and positive references, which is central for freelancers, is determined by demanding jobs. Factor 3 ("clarity of roles and tasks") is a typical aspect for freelancers as the danger of knowledge gaps or misunderstandings in the context of temporary employment is higher than in permanent employment. Clarity of roles and tasks are thus important to avoid misunderstandings and a time-consuming, nonproductive role and task determination. Place of work and working time are bundled in the aspect of work organisation (factor 4, "flexible work organisation"). Regarding the mean, the need for time-related flexibility is comparatively stronger than the need for place-related flexibility. This may last but not least be seen as an indication for the subjectively felt importance of social contacts that predominantly exist in the context of face-to-face-cooperation. Factor 5 ("company characteristics") combines aspects that define the employability of a freelancer. It is influenced by the acquirement of new 
know-how and, hence, continuous further education as well as the employment by a well-known company. Factor 6 ("qualification of superior and colleagues") combines the competence of superior and colleagues. It evidences that IT-freelancers who exercise highly specific tasks depend on the cooperation and communication with almost equally qualified people in the company.

Figure 4: Rotated factor solution concerning the expectations of IT-freelancers

\begin{tabular}{|c|c|c|c|c|c|c|}
\hline & factor 1 & factor 2 & factor 3 & factor 4 & factor 5 & factor 6 \\
\hline $\begin{array}{l}\text { open and honest superior } \\
\text { constructive contact with colleagues } \\
\text { good relationship with colleagues } \\
\text { information sharing with superior and colleagues } \\
\text { creative and productive environment } \\
\text { access to all information that is important for my work }\end{array}$ & $\begin{array}{l}0.75 \\
0.74 \\
0.72 \\
0.71 \\
0.52 \\
0.42 \\
\end{array}$ & & & & & \\
\hline $\begin{array}{l}\text { challenging tasks } \\
\text { room for manoeuvre and decision-making } \\
\text { diversified work }\end{array}$ & & $\begin{array}{l}0.83 \\
0.81 \\
0.76\end{array}$ & & & & \\
\hline $\begin{array}{l}\text { clear knowledge of the goals of my work } \\
\text { knowledge of the concrete claims regarding myself } \\
\text { clarity of my role in the company }\end{array}$ & & & $\begin{array}{l}0.80 \\
0.80 \\
0.60\end{array}$ & & & \\
\hline $\begin{array}{l}\text { possibility of flexible working time } \\
\text { possibility of home office }\end{array}$ & & & & $\begin{array}{l}0.86 \\
0.83\end{array}$ & & \\
\hline $\begin{array}{l}\text { work for a well-known company } \\
\text { own, well-equipped workplace } \\
\text { gain new knowledge through work }\end{array}$ & & & & & $\begin{array}{l}0.73 \\
0.63 \\
0.60\end{array}$ & \\
\hline $\begin{array}{l}\text { competent superior } \\
\text { qualified permanent employed colleagues }\end{array}$ & & & & & & $\begin{array}{l}0.74 \\
0.73\end{array}$ \\
\hline Eigenvalue & 4.76 & 2.18 & 1.83 & 1.28 & 1.21 & 1.07 \\
\hline portion of explained variance (\%) & 16.35 & 12.00 & 10.73 & 9.17 & 8.73 & 7.91 \\
\hline cumulated portion of explained variance (\%) & 16.35 & 28.35 & 39.08 & 48.25 & 56.97 & 64.88 \\
\hline arithm. mean (scale from $1=$ very important to $5=$ unimportant) & 3.20 & 3.11 & 3.14 & 2.78 & 2.64 & 2.38 \\
\hline
\end{tabular}

\subsection{Identification of freelancer clusters regarding work-related expectations of freelancers}

The objective of our cluster analysis was to identify homogeneous freelancer groups that are conclusive in themselves and differ as much as possible from other groups. For the differentiation we concentrated on work-related expectations of the freelancers. The question "What do individual freelancers expect from their work and their employer respectively" hence is the criterion for clustering. Thus, we refer to the second research aim of this paper, that is, to gain differentiated findings about the work-related expectations of freelancers.

The clustering was effected on the basis of the factor values of the six groups of expectations (factors) that were identified beforehand. The cluster analysis was effected as a cluster centre analysis. To this end, the ideal number of clusters had to be determined first which was achieved through hierarchical clustering (linkage method). The squared Euclidean distance as the measure of the heterogeneity thereby showed an excursive increase in the changeover from three to four clusters. At about $46 \%$ this jump is more than twice as high as the biggest jump of antecedent cluster mergers. The elbow criterion as a graphic method to determine the number of clusters confirms three clusters as the ideal number. In the next step the actual cluster centre analysis 
was carried out. The F-values of the variables indicate that in particular "social and cooperative working atmosphere", "challenging tasks" and "company characteristics" - each on a highly significant level - as well as "flexible work organisation" on a $10 \%$ significance level have contributed to determining the clusters. The cases are distributed among the clusters as follows: Cluster 1: 40 cases, cluster 2: 41 cases, cluster 3: 69 cases.

After the identification of the corresponding cluster for each freelancer, the different characteristics of the three groups may be pinpointed by means of mean and variation comparisons. Their interpretation focuses on the variables "social and cooperative working atmosphere", "challenging tasks", "company characteristics", and "flexible work organisation", which proved to be relevant for the cluster formation. To allow for a clear description of the clusters, the values of the unstandardised variables of the work-related expectations as well as central statistical data of the individual freelancer groups are depicted in figure 5.

Figure 5: Characteristics of freelancer groups

\begin{tabular}{|l|c|c|c|c|}
\hline characteristic* (mean; standard deviation) & cluster $\mathbf{1}$ & cluster $\mathbf{2}$ & cluster $\mathbf{3}$ & total \\
\hline social and cooperative working atmosphere & $\mathbf{n}=\mathbf{4 0}$ & $\mathbf{n}=\mathbf{4 1}$ & $\mathbf{n}=\mathbf{6 9}$ & $\mathbf{n}=\mathbf{1 5 0}$ \\
challenging task & $1.88 ; 0.44$ & $2.39 ; 0.51$ & $1.41 ; 0.38$ & $1.80 ; 0.60$ \\
clarity of roles and tasks & $2.73 ; 0.51$ & $1.85 ; 0.55$ & $1.43 ; 0.40$ & $1.89 ; 0.71$ \\
flexible work organisation & $1.86 ; 0.59$ & $2.04 ; 0.64$ & $1.75 ; 0.70$ & $1.86 ; 0.66$ \\
company characteristics & $2.68 ; 1.07$ & $2.15 ; 1.01$ & $2.01 ; 1.01$ & $2.23 ; 1.06$ \\
qualification of superior and colleagues & $2.32 ; 0.61$ & $2.85 ; 0.63$ & $2.11 ; 0.74$ & $2.36 ; 0.74$ \\
\hline age & $2.73 ; 0.94$ & $2.72 ; 0.70$ & $2.50 ; 0.92$ & $2.62 ; 0.87$ \\
years of freelance & $36.50 ; 7.89$ & $34.44 ; 6.91$ & $37.16 ; 7.21$ & $36.24 ; 7.36$ \\
number of assigning companies & $5.63 ; 4.54$ & $5.17 ; 5.12$ & $6.76 ; 5.04$ & $6.02 ; 4.95$ \\
employments in current company & $6.71 ; 6.10$ & $7.12 ; 7.89$ & $8.36 ; 7.69$ & $7.58 ; 7.36$ \\
* scale: 1 = very important to $5=$ unimportant & $4.06 ; 5.00$ & $4.16 ; 3.90$ & $4.43 ; 6.17$ & $4.25 ; 5.28$ \\
\hline
\end{tabular}

Cluster 1 bundles freelancers whose work-related expectations as regards the four central variables are averagely or less than averagely developed. Particularly expectations as regards "challenging tasks" and "flexibility of work organisation" reside on an average level as measured by their absolute values (2.73 and 2.68 on a five-point Likert scale); in comparison to the other two clusters the expectations are clearly below average. Both aspects refer directly to the tasks that are to be performed and the concrete job respectively so that these freelancers may be named "the intrinsically unambitious" following notions from motivation research. Concerning the demographic characteristics, it attracts attention that freelancers in this cluster are on average two years older than freelancers in cluster 2; however, the number of employing companies, although at a high variance, is slightly smaller. Just like cluster 1 , cluster 2 bundles freelancers whose work-related expectations as regards the four central variables are averagely or less than averagely developed. Differences to cluster 1 however result from expectations as regards "social and cooperative working atmosphere" and "company characteristics", both are clearly below the average level. They concern aspects beyond the actual job. In contrast to cluster 1, freelancers in cluster 2 may be called "the extrinsically 
unambitious". It consists of the youngest freelancers on the average and features the most homogeneous group as regards the variable age (least standard deviation).

Freelancers who may be referred to as comparatively aspiring are summarised in cluster 3 ("the ambitious"). $46 \%$ of all surveyed freelancers belong to this cluster. Their work-related expectations concerning all four central variables rise - in parts clearly above the mean. This in particular holds true for expectations regarding "social and cooperative working atmosphere" and "challenging tasks". For these variables, the mean as well as the homogeneity (standard deviation) of cluster 3 are higher than of the other two clusters. Considering the demographic characteristics, cluster 3 comprises the most experienced freelancers. On average, they are the oldest and show the longest duration of employment as regards both the employment form "freelance" and the number of employments for the current company - each at a relatively high variance within the group, though. This demonstrates that the demands regarding the employment apparently rise with increasing age and mounting experience.

Across all clusters, comparatively high expectations exist concerning the variable "clarity of roles and tasks" that was not relevant for clustering. This is not surprising as the variable deals with a specific aspect of freelance employment. Due to temporary employment the danger of role- or task-related ambiguity is bigger than in permanent employment. Obviously, clarity of roles and tasks are generally important for every freelancer.

A comparison of the average commitment of the three clusters shows only marginal differences. Overall, the commitment is highest in cluster 3 and lowest in cluster 2 (fig. 6). This ranking also holds true for a separate consideration of the affective and normative commitment, the calculative commitment, however, is highest in cluster 1.

Figure 6: Commitment of freelancers (as per cluster and total)

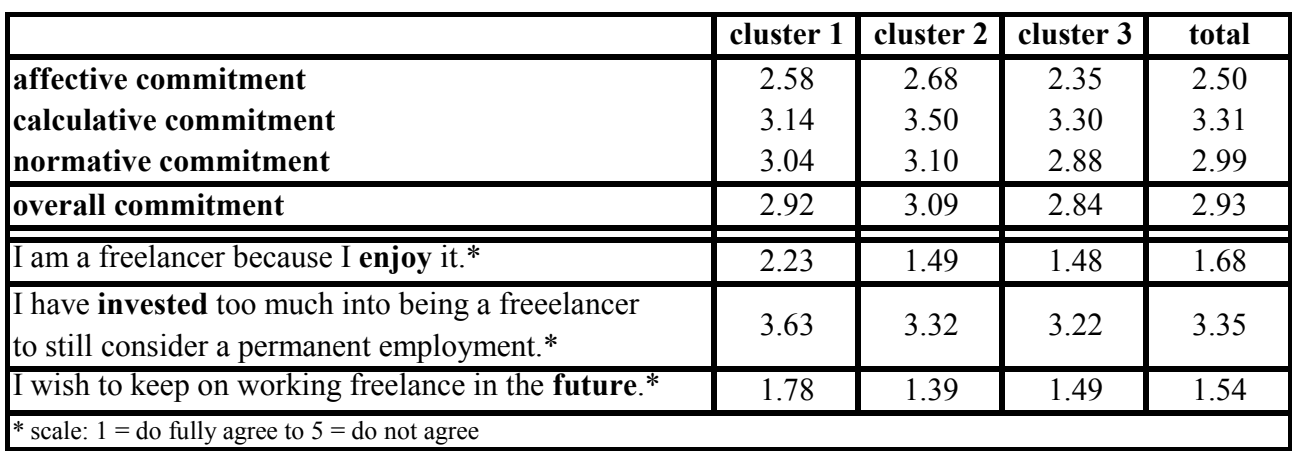

The average agreement to the statements shown in the lower part of figure 6 evidences that freelancers in cluster 1 least enjoy their work when compared to other freelancers. It hence tends to corroborate the calculative aspect. These freelancers are most of all willing to change their employment to a permanent one and - appropriately - feature the least distinctive desire to keep on working freelance in the future. Against the background of the comparatively low expectations that these freelancers have concerning their tasks, this may cautiously be seen as an indication for their 
work-related flexibility: There does neither seem to be a particular attachment to a company or to the employment form of freelancer nor to the assigned tasks. Their willingness to change company, employment status and job is presumably highest.

\subsection{Determining factors of commitment of freelancers}

The correlation between the determining factors of commitment and the commitment felt by freelancers was examined by means of multiple linear regressions. As the commitment is understood as a multi-dimensional construct following Allen/Meyer (1990), one could not act on the assumption that all determining factors influence the different commitment dimensions or the overall commitment similarly. For this reason, the influence of working conditions and personal characteristics (independent variables; fig. 2) on the different commitment dimensions (each as dependent variable) was examined separately. The regression analyses were effected on the one hand for all freelancers and on the other hand in relation to each of the determined clusters. Beforehand, the univariate normal distribution of dependent variables as the precondition for a multiple linear regression was tested for. The Kolmogorov-Smirnov test confirmed the necessary distribution. The results of the regresion analyses are shown in figure 7.

\section{Figure 7: Determining factors of commitment dimensions}

\begin{tabular}{|c|c|c|c|c|c|c|c|c|c|c|c|c|}
\hline linear regression analyses & & & & & & & & & & & & \\
\hline commitment dimensions & $\mathbf{A C}$ & $\mathbf{A C}$ & $\mathbf{A C}$ & $\mathbf{A C}$ & $\mathrm{CC}$ & $\mathrm{CC}$ & $\mathrm{CC}$ & $\mathrm{CC}$ & NC & NC & $\mathrm{NC}$ & NC \\
\hline cluster & total & 1 & 2 & 3 & total & 1 & 2 & 3 & total & 1 & 2 & 3 \\
\hline formal education & 0.07 & 0.07 & 0.02 & 0.20 & 0.00 & -0.29 & 0.05 & 0.21 & 0.08 & -0.35 & 0.13 & $0.33^{* *}$ \\
\hline $\operatorname{sex}$ & $0.14 *$ & $0.41^{*}$ & 0.11 & 0.11 & 0.15 & 0.19 & -0.12 & 0.21 & 0.04 & 0.04 & -0.07 & 0.18 \\
\hline number of assignments by the current company & $-0.15 *$ & -0.16 & -0.17 & -0.18 & -0.05 & 0.01 & -0.38 & -0.01 & $-0.22 * *$ & -0.24 & -0.37 & -0.18 \\
\hline fair remuneration & $-0.32 * * *$ & 0.05 & $-0.38 *$ & $-0.54 * * *$ & 0.04 & 0.23 & 0.09 & -0.10 & -0.16 & -0.05 & -0.24 & -0.08 \\
\hline challenging job & 0.01 & 0.07 & 0.19 & -0.11 & 0.00 & -0.22 & -0.04 & 0.18 & 0.07 & -0.08 & -0.03 & $0.24 *$ \\
\hline clarity of roles and tasks & -0.08 & -0.02 & 0.17 & -0.12 & $-0.20 *$ & 0.10 & -0.34 & -0.22 & -0.10 & -0.03 & 0.15 & $-0.29 *$ \\
\hline participating leadership & $0.26 * *$ & $0.44 * *$ & 0.01 & 0.26 & 0.17 & 0.34 & 0.05 & 0.27 & 0.18 & $0.44 *$ & 0.01 & 0.22 \\
\hline social relationship with superior & -0.18 & $-0.44 *$ & 0.10 & -0.23 & -0.21 & $-0.48^{*}$ & -0.05 & -0.05 & 0.00 & -0.36 & -0.24 & $0.47 * *$ \\
\hline competent superior & 0.15 & 0.28 & -0.19 & 0.24 & -0.03 & 0.02 & -0.05 & -0.09 & -0.05 & 0.05 & 0.09 & $-0.31^{*}$ \\
\hline positive relationship with colleagues & 0.10 & 0.17 & 0.05 & 0.06 & 0.06 & 0.02 & 0.18 & -0.18 & 0.01 & 0.06 & 0.16 & -0.09 \\
\hline positively perceived company characteristics & $0.58 * * *$ & 0.44 & 0.46 & $0.71 * * *$ & -0.15 & -0.39 & -0.17 & -0.21 & 0.21 & 0.06 & 0.44 & -0.08 \\
\hline $\mathrm{R}^{2}$ (adjusted) & $0.35 * * *$ & $0.24^{*}$ & 0.12 & $0.34 * * *$ & 0.05 & 0.17 & 0.04 & 0.02 & 0.05 & 0.05 & 0.08 & $0.22 * *$ \\
\hline $\mathrm{n}$ & 150 & 40 & 41 & 69 & 150 & 40 & 41 & 69 & 150 & 40 & 41 & 69 \\
\hline
\end{tabular}

Concerning the individual commitment dimensions the strongest correlations appear between some of the independent variables and the affective commitment; on a highly significant level $(\mathrm{p}=0.00)$, the examined independent variables explain $35 \%$ of the variance of the dependent variable "affective commitment". Thus, the general assumption that working conditions show the strongest correlations with affective commitment is confirmed (Allen/Meyer 1990; Schmidt/Hollmann/Sodenkamp 1998). As expected, the strongest positive correlations exist with the variables (1) participating leadership and (2) positively perceived company characteristics. The importance of participating leadership may be explained by the questioning of highly qualified freelancers for whom the possibility of participation represents an important claim concerning working atmosphere and job. The relevance of positively perceived company characteristics (well-known company, own and well equipped workplace, possibility to gain knowledge) may be accounted for by the specific status of freelancers who are only tempo- 
rarily employed in a company so that they have to ensure their employability beyond the borders of a particular company. This is particularly influenced by the possibility to gain knowledge as well as the image of the temporary employer. As regards the calculative commitment however, this variable has a negative influence. Company characteristics hence apparently foster commitment from an emotional point of view but not from a rational, economic standpoint. Other than expected, a clearly negative correlation exists between affective commitment and remuneration as well as number of assignments by the current company. The former evidently stands for an existing discontent with remuneration that reduces the emotional attachment. Furthermore, with increasing frequency of employment by a company, this company becomes less attractive and the commitment decreases. A possible explanation is that the view behind the curtain also brings negative experiences about so that overly positive first impressions are put into perspective in the course of time. The danger of a low commitment of freelance employees addressed in the literature hence tends to be confirmed by that (Kulkarni/Ramamoorthy 2005: 741).

The independent variables only explain $5 \%$ of the variance of each of the dependent variables calculative commitment and normative commitment respectively. Overall, only few coefficients with higher values can be found. Concerning the calculative commitment the strongest significant negative correlation exists with clarity of roles and tasks. The same applies for social relationship with superior and the participation allowed by him on a non-significant level, though. It is astonishing that the regression between the remuneration and the calculative commitment only shows a very weak positive, non-significant correlation as the assessment of remuneration expresses the cost-value ratio underlying the calculative commitment more than any other variable. Regarding the normative commitment it stands out that in comparison to the affective commitment dimension quite similar, yet weaker correlations appear with the independent variables. Given the fact that normative and affective commitment proved to be interdependent in other studies, the similar relations just as well as the negative correlation with the number of assignments by a company are however not surprising (Allen/Meyer 1990; Schmidt/Hollmann/Sodenkamp 1998: 94-96): The more frequently freelancers work in a company the lesser their normative commitment. There are highly positive, yet non-significant values for positively perceived company characteristics and participating leadership. Both obviously add to the buildup of felt obligations and, thus, normative commitment.

Differentiated by the clusters, two general results attract attention. Firstly, it becomes obvious that the examined variables averagely explain only little variance of the commitment dimensions for the second and somewhat more for the first cluster. These clusters comprise the (intrinsically or extrinsically) unambitious freelancers. Due to the low aspiration level the independent variables that refer to working conditions, that is, the job itself and its environment, do not furnish an extensive explanation for the commitment. This interpretation tends to be corroborated by the finding that these clusters show the lowest commitment (fig. 5). Secondly, the number of assignments by the company correlates negatively with all commitment dimensions across all clusters (except for the calculative commitment in cluster $1 ; \mathrm{p}=0.01$ ). This confirms the impression that with an increasing number of assignments the view behind the curtain 
generally has a - stronger or weaker - negative influence on commitment and that this may not be ascribed to the specifics of individual freelancers.

As regards the examination of differences between the clusters, deflections of the cluster-related coefficients from the overall sample are above all interesting. Cluster 3 ("the ambitious") exhibits the strongest deflections. A more differentiated analysis firstly shows that the correlations between the working conditions as the independent variable and the affective commitment are by and large less strongly positive or more strongly negative than in the other two clusters. Secondly, the most negative correlations between independent and dependent variables generally appear in cluster 3. A possible explanation for both results lies in the high claims that freelancers of this cluster have regarding the job itself as well as the working conditions. It cannot be ruled out that these claims are not (always) satisfied so that the correlations between working conditions and commitment are comparatively moderate or increasingly negative. Against this background it is however surprising that in this cluster a challenging job correlates negatively with the affective commitment. When looking at the correlations between the independent variables and the normative commitment in cluster 3, contrary to the overall sample, differences as regards the affective commitment arise. In contrast to the other two clusters, commitment to the company that forms the basis of normative commitment obviously follows in particular from a positive relationship with the superior and the satisfaction of the high expectation for a challenging job which is important for this cluster.

Cluster 1 ("the instrinsically unambitious") averagely shows the lowest deviations of cluster-related coefficients from the overall sample. Across all commitment dimensions, a participating leadership correlates positively, suprisingly however, a social relationship with the superior correlates negatively with the commitment on an after all average level. The participation in decision-making is particularly to be seen as part of work tasks that demand high qualification. In the light of the relatively low expectations that these freelancers have regarding the job itself, the offer to participate apparently fosters commitment noticeably. This does not apply for the social relationship with the superior that is beyond the actual job. Contrary to what was initially assumed, the opposite holds true. In comparison to cluster 2 ("the extrinsically unambitious") some differences may be identified (e.g. the correlation between remuneration and AC and CC respectively; participation and AC, CC and NC). Thus, for cluster 1 stronger correlations exist for many variables. An exception is represented by the remuneration which correlates clearly negatively with affective commitment in cluster 2 . This is not surprising against the background that remuneration is an aspect that classically lies beyond the job itself and that the claims of this cluster regarding extrinsic aspects are relatively low. Nonetheless, other differences may not be traced back offhand to the characteristics of the clusters. Thus, aspects that refer to the job itself or to its conditions do not offer the potential to differentiate between the two unambitious clusters.

\subsection{Limitations}

Before a final interpretation of the results, it is necessary to discuss the limitations of the research. They first of all result from the sample size that is comparatively small at 150 data records. As a consequence of the cluster analysis the overall sample was split 
into three clusters. The regression analyses hence rely on populations of 69, 41 and 40 data records. Against the background of the small (partial) samples, it is not surprising that hardly any significant coefficients could be ascertained. The explanatory power of the significance tests is limited anyway since there are restrictions regarding their applicability which result from the characteristics of a sample: Basically, significance testing only furnishes meaningful results if applied to random samples (Martin 1989: 9395). Due to the online survey, neither a representative nor - under strict standards - a random sample are existent.

Moreover, limitations for the survey ensue from sample characteristics. On the one hand, mainly men (92\%) participated in the survey so that sex-related results are hardly possible and the interpretation of the variable sex that was identified to be vital in other surveys (Gould 1975; Bruning/Synder 1983) is very restricted. On the other hand, the sample solely comprises IT-freelancers that are predominantly highly qualified. Therefore, results cannot easily be transferred to other freelancers and only have explanatory power for this group and for freelancer groups with very similar characteristics and levels of qualification.

Eventually, further limitations result from general aspects of commitment research and the questionnaire respectively. The survey confirmed that the commitment dimensions identified by Allen/Meyer (1990) overlap. Particularly the affective and normative commitment correlate noteworthily. Moreover, the use of the questionnaire that has so far been predominantly used for regular employer-employee relationships apparently underlies restrictions, too. They become apparent as the regression analyses only account for a very small proportion of the variance of the normative and calculative commitment. Against the background of this limitation, it stands to reason that the items used in the survey do not fully cover the relevant working conditions and demographic characteristics of freelancers. Besides the examined independent variables there must apparently be other factors that influence the occurrence of the calculative and the normative commitment exclusively or in a combined effect. Given the overlapping commitment dimensions, an influence of the affective commitment may be assumed. The general job motivation and the job satisfaction that have not been examined may conceivably also explain a further portion of the commitment as the literature assumes co-variegating variables in them.

\section{Conclusions and implications for further research}

Atypical employment forms have gained in importance in recent years. The practical relevance of freelancers has therefore also increased. These employment forms demand more flexibility from employees than a regular employer-employee relationship and envision a loser attachment to the company.

Against this background, the first research aim of this paper was to examine at the example of IT-freelancers whether an attachment to the employing company exists and under which conditions this applies. Principally, it was shown that the questioned freelancers feel committed so that loyalty and identification with the (temporary) employer are possible. Thereby, the affective commitment component in particular plays a vital role. A decoupling from the company cannot be substantiated even if it must be stated 
that the commitment felt by freelancers is lower than in the case of permanently employed IT-specialists in other surveys.

As regards the determining factors of commitment hypotheses were generated beforehand that were deduced from the results of other empirical studies. Not all bypotheses were confirmed: Concerning the personal characteristics, in our survey an increasing level of qualification - contrary to expectations - leads to an increase of the commitment. Regression coefficients however linger on a low level. Other than expected, the frequency of employment - as approximation of seniority - does not lead to a higher commitment. In fact, the commitment of the questioned freelancers declined with an increasing number of assignments for a company. Regarding the working conditions, the survey confirmed that challenging tasks, participating leadership, the competence of the superior, a positive relationship with colleagues and positively perceived company characteristics also foster the commitment for the questioned ITfreelancers. In contrast, role ambiguity and role conflicts respectively reduce the commitment as it has been expected. It is to be stated however that the regression coefficients are relatively weak in part and that the confirmation does not hold true for all commitment dimensions.

The second research aim of the paper was to categorise the examined freelancers regarding the criterion of their work-related expectations. It became obvious that the freelancers differ in their expectations. Besides relatively ambitious freelancers, others can be found whose expecations are low whereas a differentiation of expecations was effected regarding work-related aspects ("intrinsic") and aspects of working conditions ("extrinsic"). The clustering of freelancers allowed for a differentiated examination of the commitment and its determining factors and brought vital differences between the freelancer groups to light.

Recapitulating, the survey represents a supplement of already existing studies and, thus, the corresponding literature. Firstly, the literature on atypical employment forms is enriched. So far, it focused on the important aspect of psychological relationship between atypical employees and companies only in exceptions (Felfe et al. 2005). Secondly, the survey complements the empirical commitment research that has so far primarily referred to regular employer-employee relationships. A new perspective is therefore gained whose importance should not be underestimated given the decreasing significance of regular employment. Thereby, the necessity to take a differentiated look at commitment and its determining factors becomes particularly clear. The need for differentiation results from the various commitment dimensions and, in particular, the characteristics of the examined group (e.g. employment status, level of qualification). As shown by the clustering of freelancers, even in the relatively homogeneous group of IT-freelancers comparable relations between determining factors and commitment values do not necessarily exist. As different research results always (also) ensue from the specifics of the sample, central limitations for comparing the results with other studies become clear. General hypotheses on the influence of personal characteristics and working conditions on the commitment are hence hardly maintainable.

Eventually, some implications for further research may be derived from the present study: Further conceptual research is needed to link research on commitment to related discussions more strongly in the future. For example the literature on psychological 
contract seems to be a fruitful perspective for the topic of commitment. The theoretical substantiation of the discussion could therefore not only gain in breadth but also in depth. Besides, it is necessary to further adjust the scales of future surveys according to the characteristics of the examined sample. Although the comparability of surveys thus recedes, there is a chance to gain more comprehensive insights and, ultimately, to increase the explanatory power of independent variables. Furthermore, the question needs to be addressed as to whether the causal effect of commitment as assumed in the research design and confirmed for regular employer-employee relationships (e.g. enhanced performance, reduction of fluctuation and absenteeism) holds true for freelancers and other atypical employment forms respectively (Martin 2006).

The presented study embodies a first step to examine the psychological relationship between companies and their atypical employees empirically. In the light of the increasing practical relevance of atypical employment forms enhanced research activity in this field is however needed in the future. Studies following up on these results are hence necessary to render more up-to-date data and allow for a comparison whether the commitment of freelancers proves to be relatively stable over time. Within the scope of such studies, it seems reasonable to compare freelancers with regular employees or other forms of atypical employment that demand equal qualification and encompass similar tasks. The comparison would yield more well-defined results as regards the commitment of freelancers in relation to other employees. Moreover, it seems desirable to generate a bigger sample in order to gain more reliable results. However, there are large difficulties in identifying freelancers and making them participate in a survey. With the growing empirical relevance and the increasing level of organisation of freelancers in associations and communities, this problem could be reduced. The empirical research that is necessary because of the existing research deficit would thus considerably be facilitated.

\section{References}

Allen, N./Meyer, J. (1990): The Measurements and Antecedents of affective, continuance and normative Commitment to the Organization. In: Journal of Occupational Psychology, 63: 1-18.

Anderson, N./Schalk, R. (1998): Editorial: The psychological contract in retrospect and prospect. In: Journal of Organizational Behavior, 19: 637-647.

Angle, H./Perry, J. (1981): An Empirical Assessment of Organizational Commitment and Organizational Effectiveness. In: Administrative Science Quarterly, 26: 1-14.

Atkinson, J. W. (1957): Motivation determinants of risk tasking behavior. In: Psychological Review, 64: 359-372.

Bruning, N./Synder, R. (1983): Sex and Position as Predictors of Organizational Commitment. In: Academy of Management Journal, 26: 485-491.

Felfe, J./Schmook, R./Six, B./Wieland, R (2005): Commitment gegenüber Verleiher und Entleiher bei Zeitarbeitern. In: Zeitschrift für Personalpsychologie, 4: 101-115.

Freelancerverband (2004): Internet-Auftritt, www.freelancerverband.de (September 2004).

Gallagher, D./McLean Parks, J. (2001): I pledge thee my Troth... Contingently Commitment and the contingent Work Relationship. In: Human Resource Management Review, 11: 181-208.

Gould, S. (1975): Correlates of Organization Identification and Commitment, East Lansing.

Hackman, R./Lawler, E. (1971): Employee reactions to job characteristics. In: Journal of Applied Psychology, 55: 259-286.

Hackman, R./Oldman, G. (1976): Motivation through the design of work. In: Organizational Behavior and Human Performance, 16: 250-279.

Herzberg, F./Mausner, B./Snyderman, B. (1967): The Motivation to work. New York. 
Hoffmann, E./Walwei, U. (2002): Wandel der Erwerbsformen: Was steckt hinter den Veränderungen? In: G. Kleinhenz (Ed.): IAB-Kompendium Arbeitsmarkt- und Berufsforschung, Nürnberg: 135144.

Kieser, A. (1995): Loyalität und Commitment. In: A. Kieser/G. Reber/R. Wunderer (Eds.): Handwörterbuch der Führung. 2. ed., Stuttgart: 1442-1456.

Kulkarni, S./Ramamoorthy, N. (2005): Commitment, Flexibility and the Choice of Employment Contracts. In: Human Relations, 58: 741-761.

Luthans, F./Baack, D./Taylor, L. (1987): Organizational Commitment: Analysis of Antecedents. In: Human Relations, 40: 219-236.

Martin, A. (1989): Die empirische Forschung in der Betriebswirtschaftslehre. Stuttgart.

Martin, A. (2006): Die subjektive Beurteilung der Arbeitsbeziehung in unterschiedlichen Beschäftigungsverhältnissen. In: Die Betriebswirtschaft, 66: 146-175.

Mathieu, J./Zajac, D. (1990): A Review and Meta-Analysis of the Antecedents, Correlates and Consequences of Organizational Commitment. In: Psychological Bulletin, 108: 171-194.

Meyer, J./Allen, N. (1987): A longitudinal Analysis of the early Development and Consequences of organizational Commitment. In: Canadian Journal of Behavioral Science, 19: 199-215.

Meyer, J./Allen, N. (1991): A three-component Conceptualization of organizational Commitment. In: Human Resource Management Review, 1: 61-89.

Moldaschl, M. (2003): Von der Personalwirtschaftslehre zur Wirtschaftslehre der Person? Konsequenzen von Intrapreneuring, neuer Selbständigkeit und Ich-AG. In: M. Moldaschl/F. Thießen (Eds.): Neue Ökonomie der Arbeit, Marburg: 95-122.

Moser, K. (1997): Commitment in Organisationen. In: Zeitschrift für Arbeits- und Organisationspsychologie, 41: 160-170.

Mowday, R./Porter, L./Steers, R. (1982): Employee-Organization Linkages: The Psychology of Commitment, Absentism, and Turnover. NewYork.

Mowday, R./Porter, L./Steers, R. (2005): Do Employee Attitudes towards Organizations matter? In: K. Smith/M. Hitt (Eds.): Great Minds in Management, Oxford: 171-189.

Pfeffer, J. (2005): Working Alone: What Ever Happend to the Idea of Organizations as Communities, Stanford.

Porter, L./Steers, R./Mowday, R./Boulian, P. (1974): Organizational Commitment, Job Satisfaction and Turnover among psychiatric Technicians. In: Journal of Applied Psychology, 59: 603-609.

Riordan, C./Vandenberg, R./Richardson, H. (2005): Employee Involvement Climate and Organizational Effectiveness. In: Human Resource Management, 44: 471-488.

Rhodes, S./Steers, R. (1981): Conventional vs. Worker-Owned Organizations. In: Human Relations, 34: 1013-1035.

Salancik, G. (1977): Commitment and the Control of Organizational Behavior and Belief. In: B. Staw/G. Salancik (Eds.): New Directions in Organizational Behavior, Malabar: 1-54.

Schmidt, K./Hollmann, S./Sodenkamp, D. (1998): Psychometrische Eigenschaften und Validität einer deutschen Fassung des „Commitment“-Fragebogens von Allen und Meyer (1990). In: Zeitschrift für Differentielle und Diagnostische Psychologie, 19: 93-106.

Six, B./Felfe, J./Schmook, R./Knorz, C. (2002): Commitment in neuen Arbeits- und Organisationsformen. Halle.

Statistisches Bundesamt (2003): Bevölkerung und Erwerbstätigkeit 2002. Beruf, Ausbildung und Arbeitsbedingungen der Erwerbstätigen (Ergebnisse des Mikrozensus), Fachserie 1, Reihe 4.1.2, Wiesbaden.

Steers, R. (1977): Antecedents and outcomes of organizational Commitment. In: Administrative Science Quarterly, 22: 46-56.

Storey, J./Salaman, G./Platman, K. (2005): Living with enterprise in an enterprise economy: Freelance and contract workers in the media. In: Human Relations, 58: 1033-1054.

Tett, R./Meyer, J. (1993): Job Satisfaction, Organizational Commitment, Turnover Intention, and Turnover: Path Analyses Based on Meta-Analytic Findings. In: Personnel Psychology, 46: 259-294.

Torka, N./Looise, J./van Riemsdijk, M. (2005): Commitment and the New Employment Relationship. Exploring a Forgotten Perspective: Employers Commitment. In: Management Revue, 16: 529-539.

Vroom, V. (1964): Work and Motivation. New York.

Williamson, Oliver E. (1975): The Economic Institutions of Capitalism. New York. 